Review

\title{
Structural basis of transcription elongation
}

\author{
Fuensanta W. Martinez-Rucobo, Patrick Cramer* \\ Gene Center and Department of Biochemistry, Center for Integrated Protein Science Munich (CIPSM), Ludwig-Maximilians-Universität München, Feodor-Lynen-Str. 25, \\ 81377 Munich, Germany
}

\section{A R T I C L E I N F O}

\section{Article history:}

Received 12 June 2012

Received in revised form 6 September 2012

Accepted 7 September 2012

Available online 13 September 2012

\section{Keywords:}

Gene transcription

RNA polymerase

Elongation complex structure

\begin{abstract}
A B S T R A C T
For transcription elongation, all cellular RNA polymerases form a stable elongation complex (EC) with the DNA template and the RNA transcript. Since the millennium, a wealth of structural information and complementary functional studies provided a detailed three-dimensional picture of the EC and many of its functional states. Here we summarize these studies that elucidated EC structure and maintenance, nucleotide selection and addition, translocation, elongation inhibition, pausing and proofreading, backtracking, arrest and reactivation, processivity, DNA lesion-induced stalling, lesion bypass, and transcriptional mutagenesis. In the future, additional structural and functional studies of elongation factors that control the EC and their possible allosteric modes of action should result in a more complete understanding of the dynamic molecular mechanisms underlying transcription elongation. This article is part of a Special Issue entitled: RNA polymerase II Transcript Elongation.
\end{abstract}

(C) 2012 Elsevier B.V. All rights reserved.

\section{Introduction}

Structural studies have revealed a conserved architecture, active center, and fundamental transcription mechanism for cellular RNA polymerases [1-8]. Whereas bacteria and archaea contain a single multisubunit RNA polymerase (Pol), eukaryotic transcription relies on three essential RNA polymerases, Pol I, Pol II and Pol III, which synthesize mainly ribosomal, messenger, and transfer RNA, respectively. In plants, two additional RNA polymerases, Pol IV and Pol V, generate non-coding RNA transcripts and mediate gene-silencing processes $[9,10]$. Although Pol IV and Pol V have not been characterized structurally, both enzymes are highly related to Pol II since they contain subunits that are identical or homologous to the Pol II subunits [11]. All cellular RNA polymerases contain a highly conserved catalytic center implemented onto a conserved double psi $\beta$-barrel in the largest subunit that is shared with RNA-dependent RNA polymerases, indicative of a common ancestor [12-15]. Eukaryotic polymerases comprise a conserved ten-subunit core and up to seven additional subunits on the periphery. For transcription initiation, the eukaryotic enzymes form topologically conserved initiation complexes on promoter DNA [16]. Initiation involves promoter binding, DNA opening, and initial RNA synthesis, and is completed when the polymerase dissociates from initiation factors, escapes from the promoter, and forms a stable elongation complex (EC) [17-21].

\footnotetext{
is This article is part of a Special Issue entitled: RNA polymerase II Transcript Elongation.

* Corresponding author.

E-mail address: cramer@LMB.uni-muenchen.de (P. Cramer).
}

Most structural studies of RNA polymerases have been carried out with Pol II. Structural information on Pol II was first provided by electron microscopy (EM) [22-25], and later by low-resolution X-ray analysis [26]. Determination of the crystal structure of the tensubunit core of Saccharomyces cerevisiae Pol II in free form at $2.8 \AA$ resolution [3] and in complex with a tailed DNA template and RNA at 3.3 Å resolution [27] provided detailed information on polymerase structure and its interactions with nucleic acids. Backbone models of the complete 12-subunit Pol II were subsequently obtained [28,29] and revealed that the Rpb4/7 subcomplex protrudes from the core enzyme. A refined structure of the complete, 12-subunit Pol II was later obtained at $3.8 \AA$ resolution by combining the core enzyme structure with a 2.3 A structure of free Rpb4/7 [30]. The structures of core and complete Pol II provided powerful instruments for structure solution of Pol II complexes with nucleic acids and additional factors through molecular replacement [1]. Similarly, structures of bacterial RNA polymerases [7,8] enabled modeling [31-33] and structure determination $[34,35]$ of the bacterial EC.

Here we summarize structural studies of complexes of cellular RNA polymerases with nucleic acids, and present our current understanding of the mechanisms of transcription elongation that resulted from these studies. We concentrate on cellular transcription, and thus structural studies of ECs of bacteriophage RNA polymerases [36-40] are not discussed here, although they provided many fundamental insights into the principles of transcription elongation.

\section{Elongation complex structure and maintenance}

The first structural information on a Pol II EC was provided by an EM reconstruction that revealed downstream DNA entering the active 
center cleft of core Pol II [41]. Subsequent X-ray crystallography of core Pol II transcribing a tailed-template DNA confirmed the location of downstream DNA in the cleft, and visualized a 9-base pair DNARNA hybrid duplex emanating at right angles to the incoming DNA from the active site at the floor of the cleft [27]. These observations were consistent with results for the bacterial EC obtained by atomic force microscopy [42], and with structural models for the EC [31,32] that were based on the first crystal structure of a bacterial RNA polymerase [8] and on crosslinking [43-45]. Crosslinking also located downstream DNA in the cleft of an archaeal RNA polymerase, albeit in an initiation complex [46]. Subsequent higher-resolution EC structures of core Pol II $[47,48]$ and complete Pol II [49] with synthetic nucleic acid scaffolds provided a comprehensive view of the EC, including nucleotides upstream of the hybrid and interactions of nucleic acids with polymerase domains involved in EC maintenance (Fig. 1).

In the EC, incoming (downstream) DNA is unwound before the active center, allowing the template single strand to reach the active site, and is rewound to form the exiting (upstream) DNA duplex (Fig. 1). Within the unwound region (the transcription bubble), the growing RNA is attached to the catalytic site with its 3'-end and forms an 8-9 base pair hybrid duplex with the DNA template strand [19,48-50]. The upstream DNA duplex and the non-template strand in the bubble are mobile, but were located with the use of fluorescence resonance energy transfer experiments (Fig. 1A) [51,52]. The arrangement of nucleic acids in the Pol II EC is very similar in crystal structures of a bacterial EC that additionally revealed exiting upstream RNA in a previously proposed exit channel $[34,35]$. Many mutations in the genes encoding RNAP subunits were rationalized with the EC structure [53]. The DNA-RNA hybrid duplex is the distinguishing feature of the EC, and binds within the active center cleft to adopt a conformation that is close to an A-form duplex. The hybrid-binding site cannot bind a B-form DNA-DNA duplex, but an A-form RNA-RNA duplex is accommodated [14]. This explains how cellular RNA polymerases can have some RNA templatedependent RNA synthesis activity, and indicates that all cellular RNA polymerases might have evolved from an ancient replicase that duplicated RNA genomes.

During elongation, the polymerase maintains the transcription bubble. This requires unwinding of the downstream DNA duplex, and separation of the RNA product from the DNA template at the end of the hybrid duplex. DNA unwinding is apparently achieved by positively charged residues in the polymerase switch 2 region that 'pull' the
A

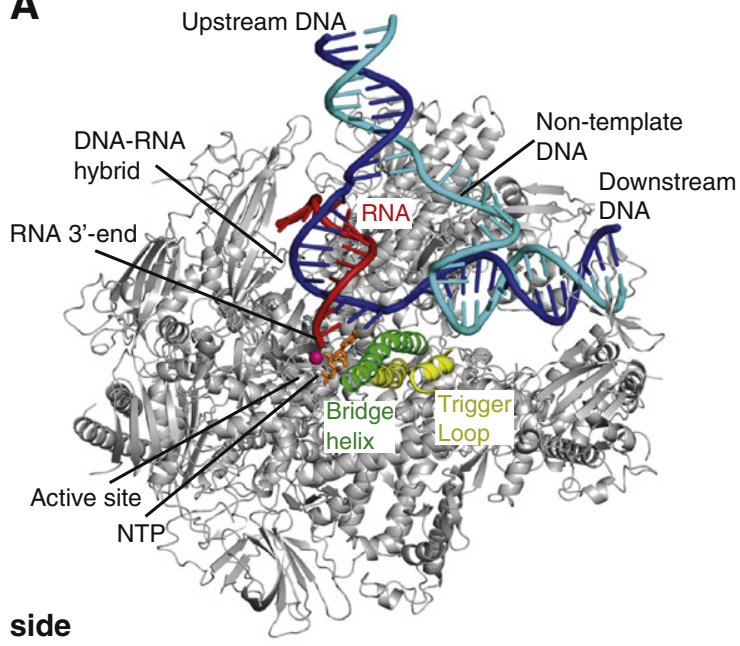

C

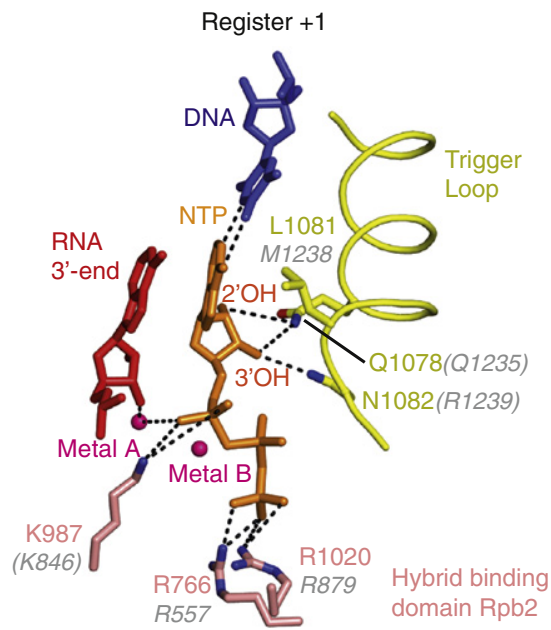

B

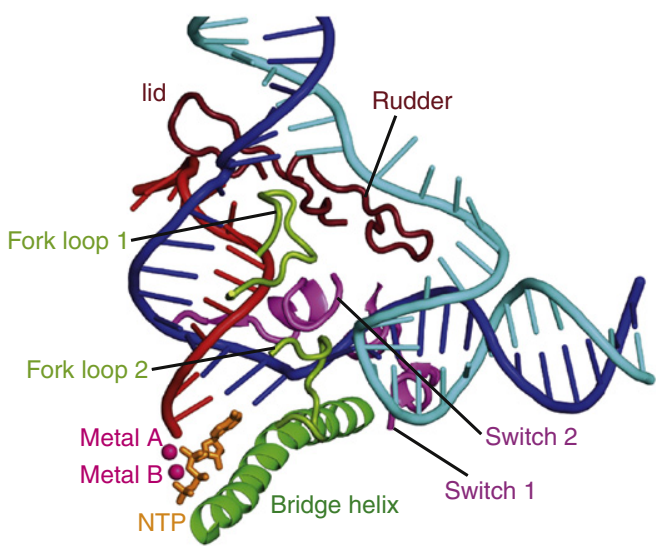

D

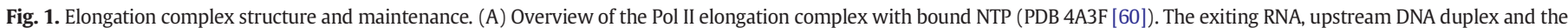

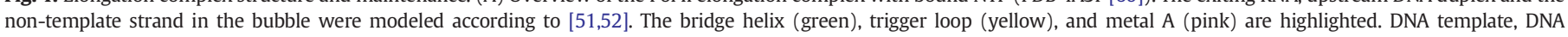

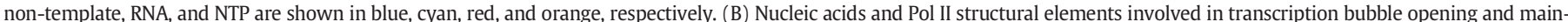

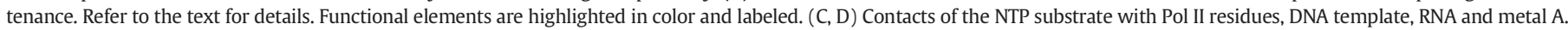

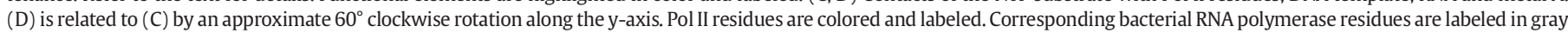
[35]. Bacterial residues that do not contact the nucleotide are indicated in brackets. Metal B was modeled in (B, C, and D) by superposition of a bacterial EC (PDB 205J) [35]. 
DNA template strand away from the non-template strand in the incoming duplex, and maybe by negatively charged residues in the switch 1 region that repel the DNA strand [49,54]. Additionally, fork loop 2 interferes with the course of the non-template strand, but it is not required for DNA strand separation in vitro [55]. RNA strand separation at the upstream end of the hybrid was suggested to involve three polymerase loops: the lid, rudder, and fork loop 1 [27,48,49]. The lid can prevent formation of extended DNA-RNA duplexes, and is important for stabilizing the open promoter complex during initiation [54,56,57]. The rudder interacts with DNA and prevents re-association with RNA, contributing to EC maintenance $[8,27,48,58]$. Fork loop 1 interacts with RNA and may contribute to maintenance of hybrid length [48], nevertheless it is not required for in vitro transcription [54]. Taken together, these polymerase elements in the cleft contribute to nucleic acid strand separation (Fig. 1B), but competition between the non-template DNA strand and the RNA transcript for base-pairing with the DNA template strand is also important for maintaining EC structure and function.

\section{Nucleotide selection and addition}

During elongation, Pol II catalyzes the DNA-directed addition of nucleotides to the growing RNA chain. In the nucleotide addition cycle (NAC), the polymerase selects the correct NTP, adds a nucleotide to the RNA 3'-end, releases a pyrophosphate $\left(\mathrm{PP}_{\mathrm{i}}\right)$ ion, and translocates along DNA and RNA to free the nucleotide addition site (register +1 ), allowing for binding of the next NTP (Fig. 2). The NAC was elucidated with NTP-containing EC crystal structures of Pol II $[47,49,59,60]$ and of a bacterial RNA polymerase [35].

The NTP substrate base-pairs with the DNA template base at register +1 , and binds in-between the RNA 3 '-end, and the polymerase bridge helix and trigger loop, two essential elements of the polymerase active center (Fig. 1A and C). NTP binding involves structural rearrangements of the bridge helix and the trigger loop, which are required for NTP positioning, catalysis, transcription fidelity, and translocation $[35,59,61,62]$. Residues contacting the NTP are conserved in all cellular RNA polymerases, consistent with a universal mechanism of NTP selection and nucleotide incorporation. The NTP substrate was observed in two overlapping but slightly different positions in the active center $[35,49,63,64]$. In addition, a non-templated NTP site was observed [47], but its functional significance remains unclear. Further, a DNA-templated NTP site at position +2 , downstream of the active site, was proposed based on kinetic studies $[65,66]$, but was detected neither biochemically nor structurally thus far.

From the above studies, the following view of the NAC has emerged, which may be extended when additional data become available. The NTP substrate binds transiently to an open active center conformation

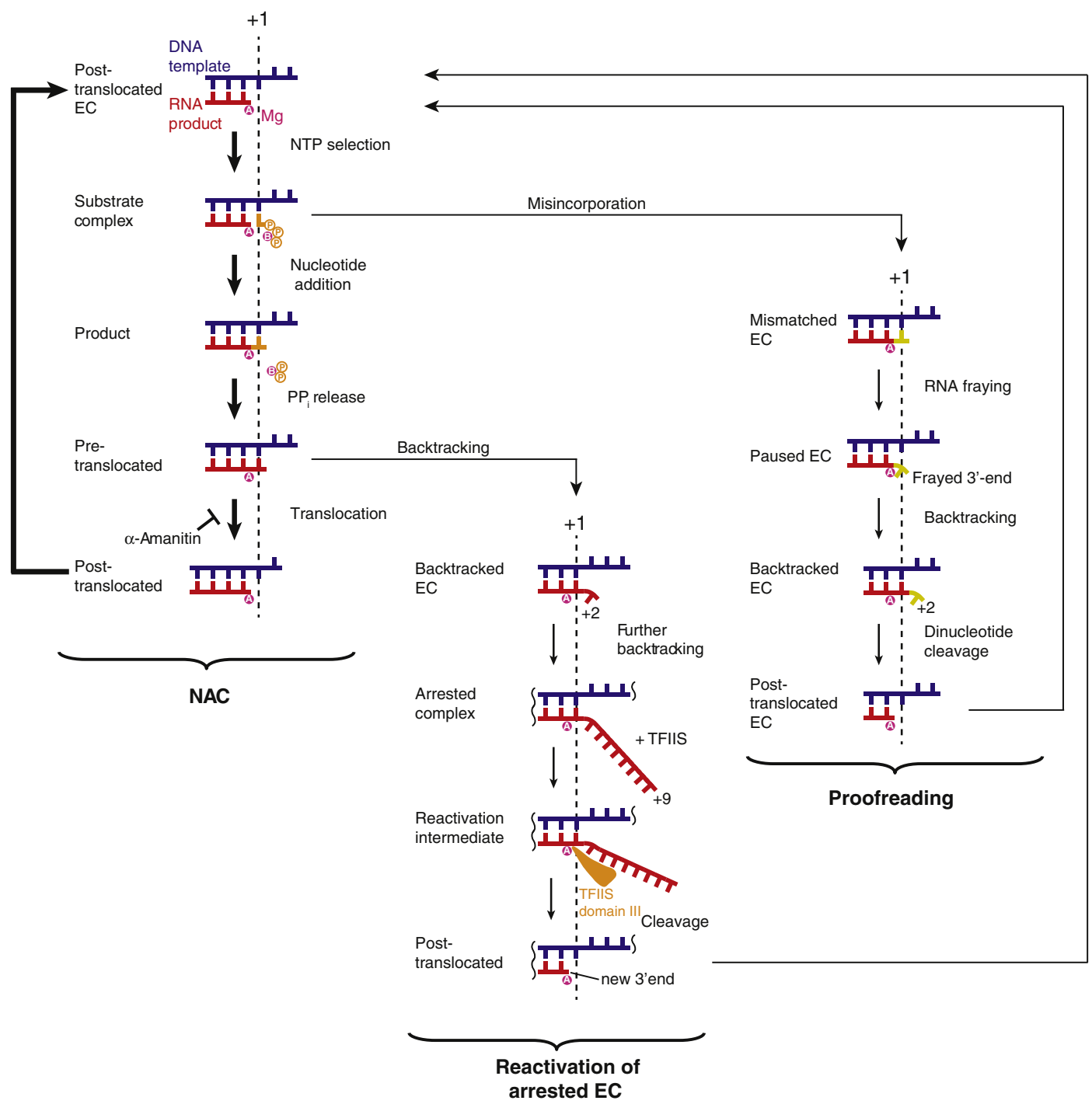

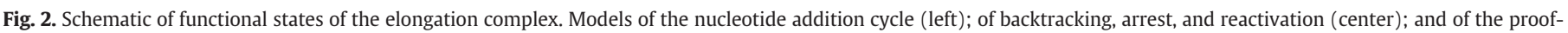
reading cycle (right). Register +1 (nucleotide addition site) is indicated by a vertical dashed line. 
with a mobile trigger loop (Fig. 3), adopting a catalytically inactive pre-insertion state. A cognate NTP then induces folding of the trigger loop into an $\alpha$-helical hairpin, which closes the active center, and a shift of the NTP to the insertion site that results in formation of all contacts required for catalysis (Fig. 1C and D). This two-step mechanism of NTP selection explains selection of the correct NTP, which is important for assuring transcription fidelity. Binding of a non-complementary NTP shifts the equilibrium between the closed and open conformations of the active site towards the open conformation, making release of the incorrect NTP more likely than nucleotide incorporation, thereby impairing misincorporation [67]. A two-step mechanism of substrate selection was also described for the unrelated phage T7 RNA polymerase $[38,68]$ but involves two spatially separated pre-insertion and insertion sites, in contrast to cellular RNA polymerases.

For catalytic nucleotide addition, RNA polymerases use a two-metal ion mechanism [69,70]. In the Pol II active site, one metal ion (metal A) is persistently bound, and a second metal ion (metal B) is mobile [3]. Metal A binds the RNA 3'-end, and is held by three conserved aspartate side chains (D481, D483, and D485) of the aspartate loop in the largest polymerase subunit (Fig. 1D) [3,71], whereas metal B binds the NTP triphosphate moiety, and is located near residues D481 and D483 of Rpb1, and the highly conserved residues E836 and D837 of Rpb2 [3,47]. Catalysis apparently follows a nucleophilic substitution $\left(\mathrm{S}_{\mathrm{N}} 2\right)$ mechanism, with the RNA 3'-OH group acting as the nucleophile that attacks the NTP $\alpha$-phosphate. After nucleotide addition, release of a pyrophosphate $\left(\mathrm{PP}_{\mathrm{i}}\right)$ ion may cause trigger loop unfolding and opening of the active center to restart the NAC [72,73].

RNA polymerases discriminate NTP from dNTP by recognition of the 2 '-OH group of the ribose. Bacterial RNA polymerase has a 1000 -fold preference of NTP over dNTP [62,74], whereas yeast Pol II shows a 500- to 5000-fold selectivity of NTPs relative to dNTPs [75]. A conserved asparagine residue in the active center, $N \beta^{\prime} 458$ and Rpb1 N479 in E. coli and yeast RNA polymerases, respectively (Fig. 1D), was proposed to play a role in NTP/dNTP discrimination by contacting the ribose 2 '-OH group $[27,74,76]$. Indeed, mutation of these residues decreased NTP/ dNTP discrimination [59,74]. Structural work on T. thermophilus RNA polymerase showed that the equivalent asparagine (Asn $\left.\beta^{\prime} 737\right)$ forms hydrogen bonds with both the $2^{\prime}$ - and $3^{\prime}-\mathrm{OH}$ groups of the ribose, and that the conserved R $\beta^{\prime} 704$ (yeast Rpb1 R446) contacts the $2^{\prime}-\mathrm{OH}$ group [35]. NTP contacts with the trigger loop are also involved in substrate selection. Yeast Rpb1 residue N1082 contacts the ribose $3^{\prime}-\mathrm{OH}$ group, and Rpb1 L1081 and the corresponding T. thermophilus M $\beta^{\prime}$

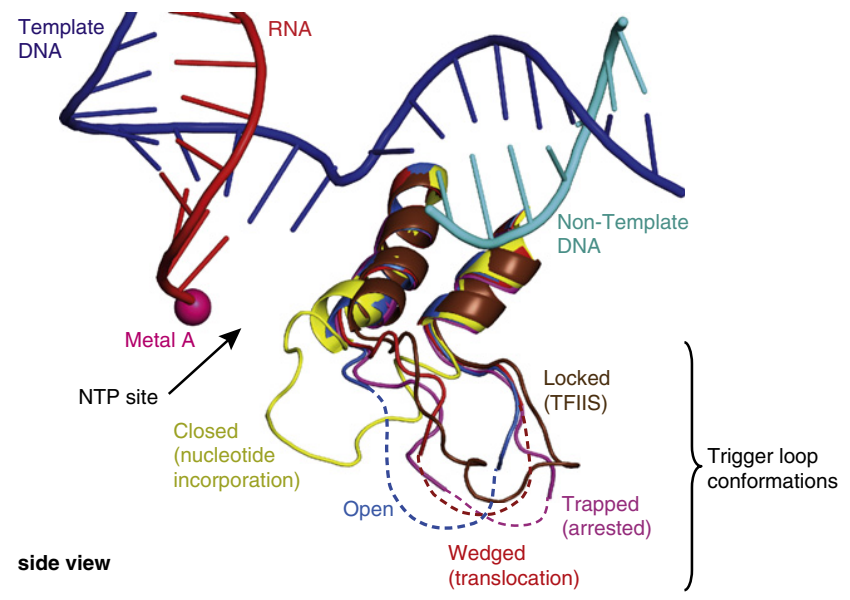

Fig. 3. Comparison of trigger loop conformations. Superposition of the five Pol II trigger loop (TL) conformations known structurally. Open TL in the post-translocation state (PDB 1Y1W [49], blue), closed TL in the nucleotide incorporation state (PDB 2E2H [59], yellow), wedged TL in the translocation intermediate (PDB 2VUM [61], red), trapped TL in the arrested complex (PDB 3PO2 [107], violet), and locked TL in the reactivation intermediate (PDB 3 PO3 [107], brown). DNA template (blue), DNA non-template (cyan), RNA (red) and metal A (pink) are from the open state.
1238 stack onto the base moiety [59,61,62,75,77]. Recent work revealed an additional contact between the NTP ribose 2 '-OH group and trigger loop residue Q1078 (Fig. 1D) that likely contributes to NTP selection [60].

\section{Translocation and inhibition}

After addition of a nucleotide to the growing RNA chain, the polymerase is in a pre-translocation state and the insertion site is occupied by the newly extended RNA 3'-end. To free the insertion site for binding of the next NTP, the polymerase must translocate along DNA by one register, passing on to the post-translocation state (Fig. 2). Comparative analysis of bacterial RNA polymerase and Pol II core structures initially suggested that a conformational change of the highly conserved bridge helix (from straight to bent) underlies translocation [3,8,27]. The location of the bridge helix at the downstream end of the pre-translocated hybrid, and its possible partial movement toward the hybrid was suggested to accompany nucleic acid movement. A later structure of another bacterial RNA polymerase revealed that the central region of the bridge helix can be flipped out, and that this may be influenced by the adjacent trigger loop [7]. Alternative conformations of the bridge helix were observed within the same RNA polymerase, and supported the functional relevance of bridge helix movement [78,79].

Biochemical and mutational studies of bacterial RNA polymerase revealed the functional cooperation of the bridge helix and trigger loop, and suggested detailed models of translocation [80,81]. The importance of the bridge helix and trigger loop in determining the polymerization rate is well documented by mutational analysis [82,83]. Translocation apparently involves a Brownian ratchet, although this remains debated [84]. The ratchet model proposes that after nucleotide incorporation, the EC exists in an equilibrium between the preand post-translocation states, and that the binding of the next incoming NTP captures the post-translocated state.

The mechanism of translocation was elucidated with structures of Pol II bound by the mushroom toxin $\alpha$-amanitin $[61,75,87]$. An initial crystallographic analysis of core Pol II in complex with $\alpha$-amanitin showed that the toxin binds to the polymerase pore and funnel beneath the active center next to the bridge helix, and this suggested that the inhibitor interferes with bridge helix movement during translocation [87]. The idea of translocation inhibition by $\alpha$-amanitin is supported by kinetic data [88]. However, in the Pol II-amanitin complex, $\alpha$-amanitin bound only one residue in the bridge helix and this residue was not in the region of the bridge helix that changed conformation. Rerefinement of the Pol II core- $\alpha$-amanitin structure $[75,87]$ later revealed new contacts between the inhibitor and the trigger loop, and suggested that the toxin interferes with movement of the trigger loop [59] and thus with the Brownian ratchet.

Structural studies of a Pol II EC bound to $\alpha$-amanitin [61] revealed additional interactions between the inhibitor and Pol II and further elucidated the mechanism of translocation. $\alpha$-Amanitin binding trapped the EC in a new conformation that was intermediary between the pre- and post-translocated structures (Fig. 3, wedged TL). Previous EC structures all adopted the post-translocation state, except for the initial Pol II core structure with a transcribed tailed template, which adopts the pre-translocation state $[27,34,48]$. The intermediate state of the EC revealed a specific, new conformation of the bridge helix and trigger loop. The trigger loop had formed a wedge adjacent to the central portion of the bridge helix and shifting its position to occlude the site for the +1 templating DNA base. The DNA-RNA hybrid adopted the post-translocation state, whereas the DNA template base was flipped out of the active site and resided in a pre-templating position above the bridge helix. These observations led to the proposal of a two-step mechanism for translocation [89]. In a first step, the polymerase trigger loop and bridge helix cooperate to accompany movement of the nascent hybrid base pair out of the active site, and translocation of the next template base into a pre-templating position 
above the bridge helix. In a second step, relaxation of the shifted bridge helix allows the DNA template base to enter the active site by a 90 -degree twisting motion. Thus $\alpha$-amanitin inhibits Pol II by trapping the Brownian ratchet consisting of the trigger loop and bridge helix, which impairs Pol II translocation and subsequent nucleotide incorporation.

After translocation, NTP binding and nucleotide incorporation generate a pyrophosphate ion. In statu nascendi the pyrophosphate ion is bound between the active site and the closed trigger loop. Release of the pyrophosphate ion would re-mobilize the trigger loop, which can then open and swing underneath the bridge helix, allowing for bending of the bridge helix and translocation. In this model, pyrophosphate release remobilizes the Brownian ratchet, which in turn enables translocation. However, pyrophosphate release does not drive translocation directly, as predicted by the power stroke model, an alternative model for translocation. Experimental $[72,85]$ and computational $[73,90]$ evidence generally agrees with the Brownian ratchet model. To illustrate our current understanding of the translocation mechanism, we have previously animated the nucleotide addition cycle $[63,86]$ and this animation is available for download at http://www.cramer.genzentrum.lmu.de/movies/. We have also included this animation in a recent movie of Pol II transcription that can be used for teaching purposes and downloaded from the publisher's website as a supplementary file [63,86].

Structures of bacterial RNA polymerases in complex with inhibitors have also trapped functional states of the EC. The antibiotic streptolydigin (Stl) traps bacterial RNA polymerase in an inactive pre-insertion state $[35,79,91]$. Stl prevents folding of the trigger loop and blocks full NTP delivery to the insertion site [35,92]. The structure of bacterial RNA polymerase with the inhibitor Tagetitoxin (Tgt) indicated that Tgt stabilizes an inactive state by changing metal ion binding in the active site $[91,93]$. However, a recent EC-Tgt model based on biochemical analysis and molecular dynamic simulations suggested that Tgt inhibits transcription by trapping the trigger loop in an inactive state [94]. Thus the mechanism of Tgt inhibition remains debated $[95,96]$

Structural studies of bacterial RNA polymerase in complex with an inhibitory protein, the initiation and elongation inhibitor Gre factor homologue 1 (Gfh1), revealed that Gfh1 interacts with the trigger loop and bridge helix to prevent NTP binding. The structure also revealed a new polymerase conformation, called a 'ratcheted state', in which two mobile polymerase modules, the core and shelf modules [3], are observed in a new relative position obtained after an apparent ratcheting motion relative to each other, and the polymerase clamp has also moved relative to the shelf module [97]. The new conformation was proposed to represent a translocation intermediate, but it remains to be seen whether in the absence of Gfh1 this conformation can be adopted by the EC, or whether it is a feature of the free polymerase only. Taken together, inhibitors of bacterial and eukaryotic RNA polymerases impair transcription elongation by trapping mobile elements of the active center, including the bridge helix, trigger loop, and switch regions. Inhibitors of transcription initiation have also been investigated but are not discussed here, and include rifampicin [78,98,99], sorangicin [100], and myxopyronine [101].

\section{Pausing and proofreading}

In the course of elongation, polymerase undergoes transient pausing. During pausing, transcription is only temporarily stalled, and the polymerase will eventually resume elongation. Pauses vary in duration and can be induced by certain DNA sequences, by DNA lesions (see below), by a mismatched nascent base pair resulting from a misincorporation event, or by hairpins that form in the nascent RNA. Pausing has been described as a two-tiered mechanism, with a first stage referred to as the elemental pause [102]. The elemental pause is an off-line state that is adopted after an initial rearrangement of the active site that interrupts elongation without a change in translocation register. Further rearrangements within the EC or interaction with regulators can then give rise to a long-lived pause or polymerase backtracking along DNA and RNA. It was suggested that the elemental pause is characterized by fraying of the 3'-terminal RNA nucleotide away from the DNA template [103]. Structural analysis showed that RNA fraying can occur, as a frayed RNA 3'-nucleotide was observed in a Pol II EC crystal with a mismatched base pair at the end of the hybrid $[104,105]$. The frayed 3'-nucleotide was found in two alternative sites that overlap with the NTP-binding site, explaining how nucleotide addition is prevented in the elemental pause state. The frayed base stacks onto the 'gating tyrosine' residue Y769 of the largest Pol II subunit. Whether additional conformational changes occur in a paused EC remains to be seen.

A misincorporated nucleotide can be removed from the RNA 3'end by RNA proofreading (Fig. 2). As a result of structural and biochemical work from several research groups [104,106-110], a model for transcriptional proofreading has emerged (reviewed in [105]). After nucleotide misincorporation, the mismatched 3'-nucleotide does generally not form a stable nascent base pair at register +1 but may rather fray away from the DNA template, inducing a paused state and inhibiting RNA extension. The polymerase then backtracks by one step, moving the 3 '-terminal mismatched RNA nucleotide from the fraying site to a proofreading site at register $+2[104,109]$. Backtracking by a single step aligns the scissile phosphodiester bond with the catalytic site. The RNA 3'-end then stimulates the intrinsic endonucleolytic activity of the polymerase [110]. Cleavage of a dinucleotide containing the mismatched nucleotide frees the NTP-binding site and restores the nucleophilic RNA 3'-OH group in the active site, allowing transcription to resume. Such proofreading, together with NTP selection as described above, accounts for the fidelity of transcription (reviewed in [104,105]).

\section{Backtracking, arrest, and reactivation}

During elongation, RNA polymerases can encounter DNA sequences that lead to destabilization of the DNA-RNA hybrid [111,112], polymerase backtracking, and transcription arrest [112,113]. During backtracking, the polymerase moves backwards along DNA and RNA, and the RNA 3'-end is disengaged from the active site and extruded through the pore beneath the active site into the polymerase funnel (Fig. 4A). Once arrested, the polymerase requires additional factors to be reactivated before it can continue elongation (Fig. 2). Crystallographic analysis of Pol II with DNA-RNA scaffolds allowed for the visualization of one or two backtracked RNA nucleotides in the pore [109]. Crystallographic analysis of an arrested complex formed after tailed-template transcription then enabled trapping of nine backtracked RNA nucleotides in a backtrack site, an extended and conserved binding site for single-stranded RNA in the pore and funnel (Fig. 4A and B) [107,109]. The first backtracked RNA nucleotide +2 stacks between the +1 base and Rpb2 gating tyrosine residue Y769 [107,109], which may generally delimit the extent of backtracking, and explain the preference for cleaving dinucleotides from RNA. However, at arrest sites, the DNA-RNA hybrid is weak and the RNA can backtrack beyond the gating tyrosine until it binds the backtrack site in the pore. Backtracked RNA in the pore traps the trigger loop in an inactive conformation (Fig. 3) and prevents forward translocation and NTP binding [107].

Arrested bacterial and eukaryotic RNA polymerases are reactivated by factors that stimulate transcript cleavage at the active site, the Gre factors and TFIIS, respectively [114]. Gre factors and TFIIS possess functional similarity, yet are unrelated in sequence and structure. Gre factors consist of two domains, an N-terminal antiparallel $\alpha$-helical coiled-coil domain that interacts with the RNA transcript and a C-terminal globular domain that binds RNA polymerase [115-118]. TFIIS consists of three domains, an $\mathrm{N}$-terminal four-helix bundle domain I that is not required for cleavage-stimulatory activity, a three-helix bundle domain II, which 
A

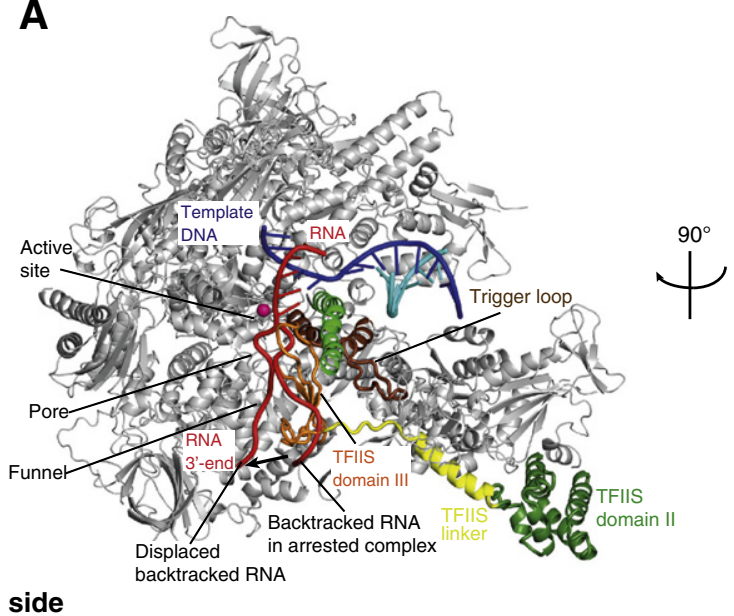

C

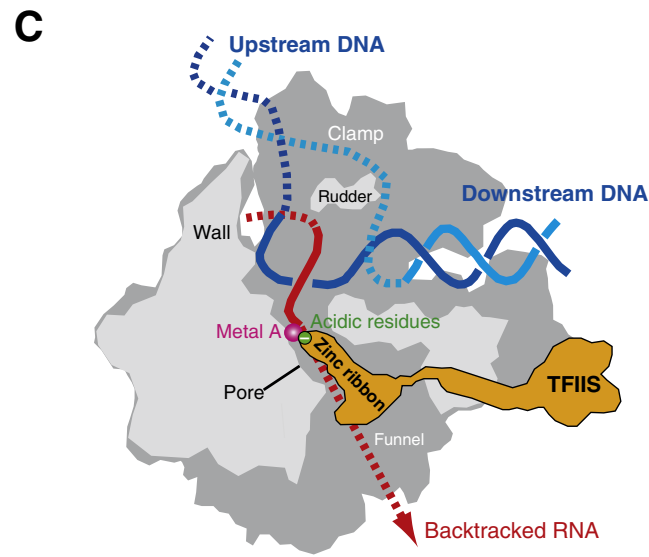

Yeast Pol II-TFIIS
B
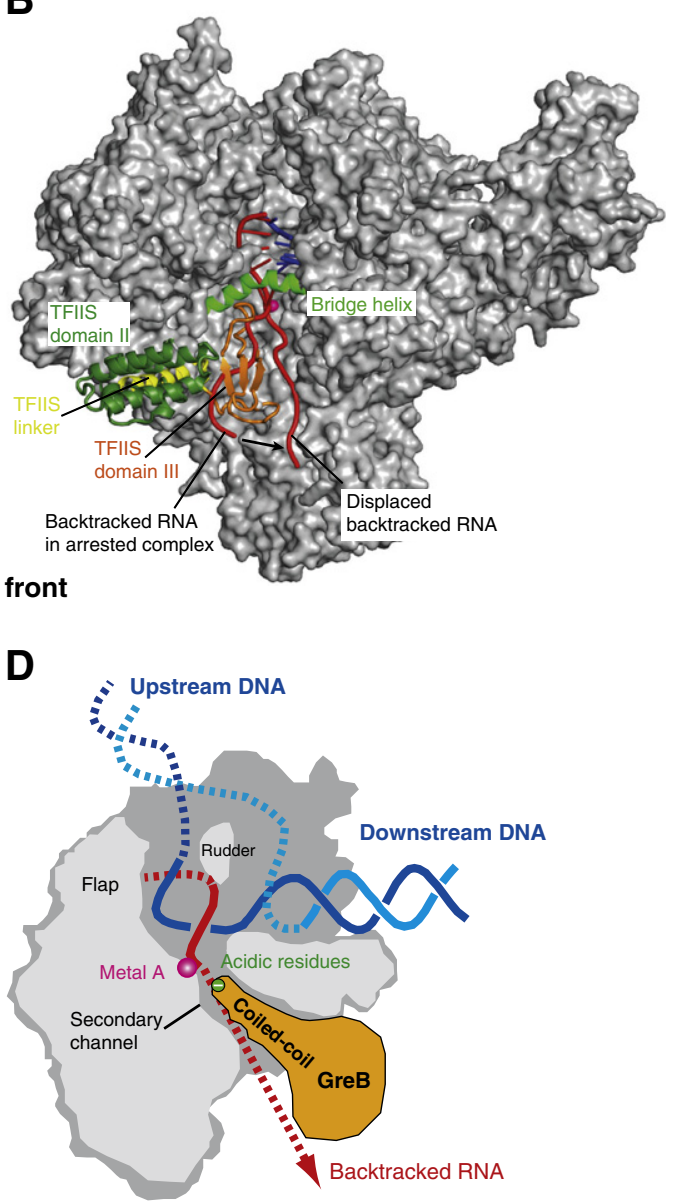

Bacterial RNA polymerase-GreB

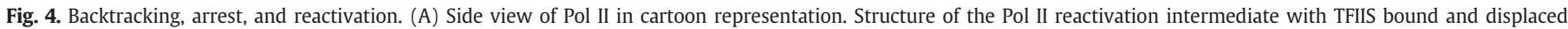

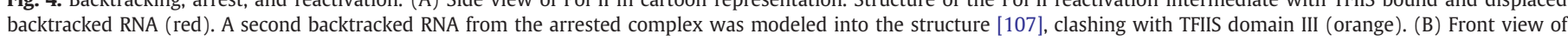

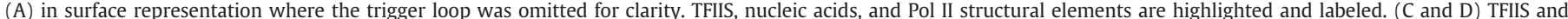

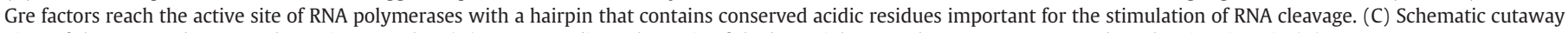
view of the yeast Pol II-TFIIS elongation complex. (D) Corresponding schematic of the bacterial RNA polymerase-GreB complex. The view is as in (A).

is required for Pol II binding, and a zinc ribbon fold domain III, which is required for RNA cleavage [119-121].

Structural studies of yeast Pol II and the Pol II EC in complex with TFIIS $[49,76,107,109]$ revealed the mechanism of TFIIS function. The first structure of a Pol II-TFIIS complex showed that TFIIS spans the polymerase surface from one of the jaws to the active site, and provided evidence that the polymerase contains a single, tunable active site that can switch between polymerization and cleavage modes [76], consistent with earlier proposals [122-124]. A comparison with previous Pol II structures revealed major TFIIS-induced conformational changes in Pol II that realign RNA in the active center, as confirmed in a subsequent structure of a Pol II-EC-TFIIS complex [49]. EM studies of a bacterial RNA polymerase-GreB complex showed that the Gre factor also inserts into the polymerase pore (called the secondary channel in bacterial polymerase) and reaches the active site with its N-terminal domain [116]. Although there are no structural similarities between TFIIS and GreB, both factors reach the active site with a hairpin that contains conserved acidic residues that are important for RNA cleavage stimulation. Thus, a similar topological mechanism for stimulated transcript cleavage and polymerase reactivation after arrest resulted from convergent evolution of the two transcription systems (Fig. 4C and D).

Crystal structures of Pol II in complex with TFIIS revealed details of the mechanism of TFIIS-induced polymerase reactivation $[49,107,109]$. TFIIS domain III inserts into the pore, locking the trigger loop away from backtracked RNA and releasing backtracked RNA from the backtrack site (Fig. 4A and B). The conserved hairpin in domain III reaches the active site and complements Pol II with three charged residues, two acidic residues and one basic residue. A two-metal ion mechanism for TFIIS-dependent RNA cleavage stimulation was proposed [69,76,107]. In this model, metal A is persistently bound to the active site, whereas metal $B$ is recruited and positioned by the acidic residue in the TFIIS hairpin. In contrast to its binding of the RNA 3'-hydroxyl during nucleotide addition, metal $\mathrm{A}$ binds the +1 RNA phosphate, to align the scissile phosphodiester bond (between nucleotides -1 and +1 ) during cleavage. The two acidic hairpin residues D290 and E291 may then coordinate metal B, together with the Pol II Rpb2 residue D837, and position a water molecule, which acts as the nucleophile. The TFIS hairpin residues may be required for two catalytic proton transfers, proton subtraction from the water molecule, and proton donation to the product RNA 3'-terminus. The basic TFIIS hairpin residue R287 possibly stabilizes the negatively charged transition state. After RNA cleavage and release of the terminal RNA oligonucleotide, a new RNA 3'-end is formed at the active site (Fig. 2) and elongation resumes.

\section{Transcription processivity}

Processivity refers to the property of the polymerase to remain associated with an actively transcribed DNA template in order to 
successfully reach the end of the transcription unit. Processivity is achieved, to a large extent, by the high stability of the EC, which mainly results from the tight binding of the DNA-RNA hybrid [125]. RNA polymerases however use accessory factors that reduce pausing and termination, and thus increase processivity. The factor Spt5 (NusG in bacteria), was shown in the bacterial system to stimulate transcription processivity, and is the only polymerase-associated factor that is universally conserved across the three domains of life. NusG renders the polymerase processive by increasing the pause-free speed of elongation and suppressing RNA polymerase entry into long-lived pauses [126-129]. Archaeal Spt5 was shown to stimulate elongation in vitro [129], indicating that the function in processivity is conserved in higher cells, although it has not yet been demonstrated in the eukaryotic system. Bacterial NusG and archaeal Spt5 consist of an N-terminal NGN and a C-terminal KOW domain. Eukaryotic Spt5 additionally contains an $\mathrm{N}$-terminal acidic region and additional KOW domains that together with a C-terminal repeat region (CTR) serve as a recruitment platform for additional factors (reviewed in [130]). In archaea and eukarya, Spt5 associates with Spt4 through its NGN domain to form the Spt4/5 heterodimer.

Biochemical and mutational studies suggested that NusG accelerates oscillation of the ratchet formed by the bridge helix and trigger loop $[80,131]$. It was also shown that the NGN domains of NusG and its paralog $\mathrm{RfaH}$ are sufficient for polymerase binding and reduction of transcriptional pausing $[132,133]$. Mutational analysis identified a conserved hydrophobic cavity in the NGN domain that mediates binding to the conserved coiled-coil of the polymerase clamp [129]. The NusG paralog RfaH stimulates elongation and binds to the non-template DNA strand [134], which plays a role in processivity [125].

Structural studies extended these observations and suggested the molecular basis of Spt4/5-mediated transcription processivity. EM analysis of archaeal RNA polymerase in complex with Spt $4 / 5$ showed that Spt5 spans the polymerase cleft from the clamp on one side to the lobe and protrusion on the other side [135]. A functional interaction with the lobe was indeed demonstrated for the bacterial NusG paralog RfaH [136]. Crystallographic analysis of Spt4/5 in complex with an archaeal polymerase clamp domain revealed that the Spt5 NGN domain binds to the coiled-coil of the clamp (Fig. 5A) through a conserved Spt5-polymerase interface, and enabled modeling of complexes of Spt4/5 counterparts with RNA polymerases from all kingdoms of life [137]. The models are consistent with biochemical data, indicating a universal binding mode to all polymerases. The modeling further showed that Spt5 may contact upstream DNA and the non-template DNA strand in the transcription bubble [135,137], consistent with previous biochemical studies $[134,138]$. Interactions between the positively charged Spt5 surface and the negatively charged DNA non-template strand may help to prevent collapse of the transcription bubble.

These studies indicated that the NGN domain of Spt5 spans the active center cleft, locking the nucleic acids in the cleft and preventing their dissociation (Fig. 5B). In addition, stabilizing interactions with the transcription bubble may exist, and the mechanism may also involve an allosteric component, as the clamp is connected to elements of the active center, and Spt $4 / 5$ binding could thus modulate the catalytic activity of the polymerase $[130,137]$. Additionally, the Spt5/NusG KOW domains serve as a recruitment platform for additional factors that facilitate multiple processes during elongation [130]. In eukarya, the Spt5 CTR contributes to the recruitment of 3'-RNA processing factors [139] and of the Paf1 complex [140-142], which in turn recruits factors involved in chromatin modification.

\section{DNA lesions and RNA mutagenesis}

Lesions in the DNA template strand can also impede transcription elongation. It is estimated that several thousand DNA lesions occur in a single cell per day [143]. The chemical nature of the lesion determines the fate of an elongation complex encountering the lesion. In general, bulky DNA lesions in the transcribed DNA strand (the template strand) lead to polymerase stalling and can induce transcription-coupled DNA repair (TCR) [144-146], whereas small lesions can be bypassed by the EC. The mechanism of TCR has been elucidated in bacteria $[147,148]$, but eukaryotic TCR remains poorly understood [149]. The first step in TCR is the recognition of damaged DNA by the polymerase. Structural studies of Pol II ECs containing bulky DNA lesions provided the molecular basis for the recognition of a damaged DNA template strand by Pol II [150,151].

Structure-function analysis of Pol II ECs containing a UV-induced cyclobutane pyrimidine dimer (CPD) lesion at various positions of the DNA template offered snapshots of CPD-induced stalling of Pol II [150]. Pol II stalls when a CPD reaches the active site, after misincorporating a nucleotide opposite the CPD 5'-thymine residue. During elongation on undamaged DNA, the template base at downstream position +2 is transferred to the insertion site at the +1 position by a $90^{\circ}$ twisting motion. Such twisting is however not possible for an incoming CPD, since the two thymines of the lesion are covalently linked. Therefore, the
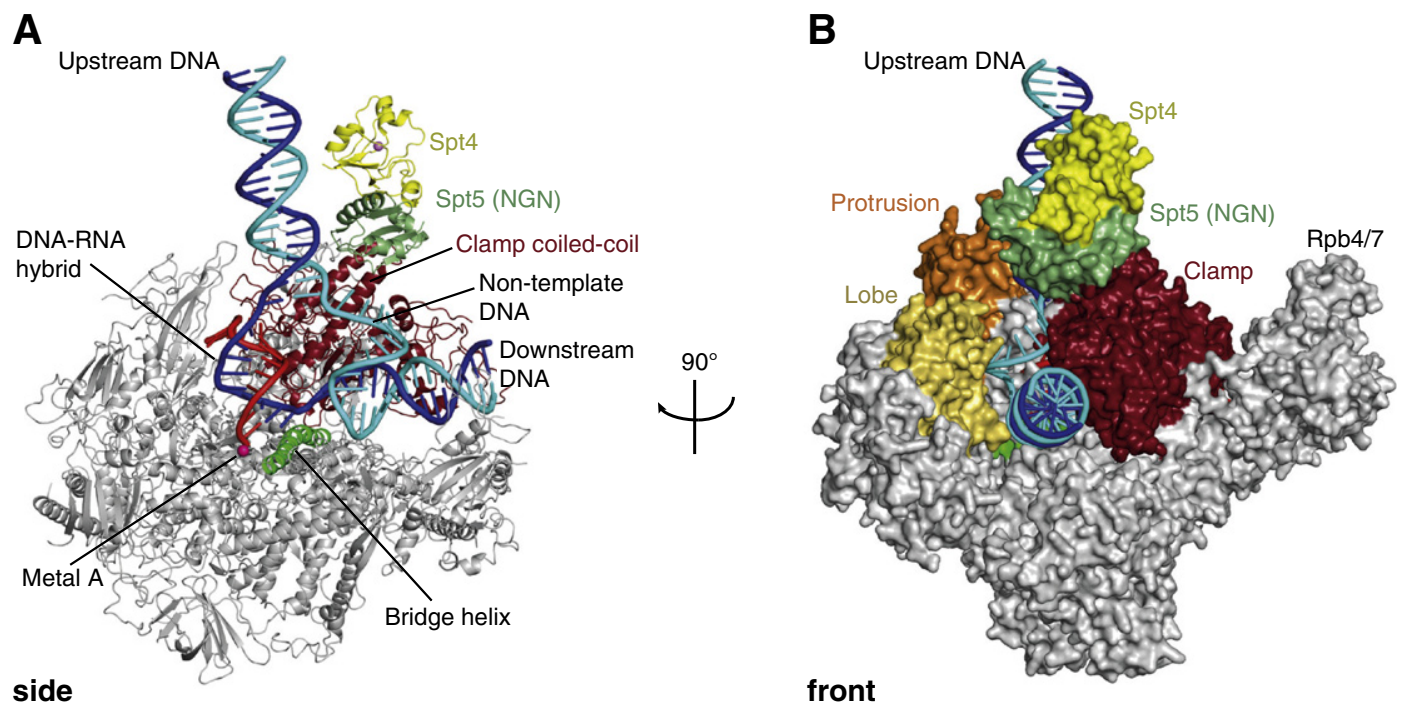

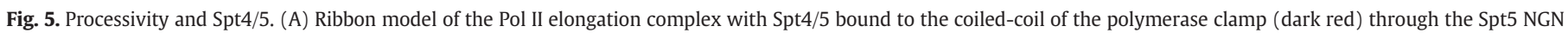
domain (pale green). (B) Front view of (A) in surface representation with key domains highlighted in color and labeled. 
CPD has to pass a translocation barrier to move into the active site [144]. This may be achieved by non-templated AMP incorporation while the CPD is still suspended downstream of the active site [144,150], according to an A-rule for non-templated nucleotide addition known for DNA polymerases [152]. The CPD then enters the active center, and the newly incorporated adenine in the RNA forms a Watson-Crick base pair with the $3^{\prime}$-thymine of the CPD. Then Pol II specifically misincorporates UMP opposite the $5^{\prime}$-thymine of the CPD [144,153].

Structures of a Pol II EC with the CPD lesion in the active site revealed the $5^{\prime}$-thymine in a wobble position that leads to slow UMP misincorporation at register +1 [150]. The resulting CPD 5'-thymineuracil mismatch blocks further translocation, resulting in Pol II stalling. Artificial replacement of the misincorporated uridine by adenosine in the RNA product enables CPD bypass, indicating that distortions due to the CPD alone are not sufficient to cause stalling and that Pol II stalling requires CPD-directed misincorporation. In the stalled complex, the lesion is inaccessible, and the polymerase conformation is unchanged. This argues against an allosteric signal for recruitment of repair factors, and suggests that a lesion-containing DNA fragment is excised in the presence of Pol II. A recent study [154] however showed that a fraction of Pol II is able to bypass a bulky UV-induced CPD during transcription. Even though most of the ECs stalled after misincorporation opposite the CPD lesion, a small amount of lesion bypass can be detected. This contributes to cellular resistance to UV-induced DNA damage, and may thus be important for exposing the lesion for subsequent repair.

Similar to CPD lesions, bulky cross-links between neighboring nucleotides of the template strand, induced by the anticancer drug cisplatin, stall Pol II and induce TCR [155,156]. In a cisplatin lesion, a platinum atom bridges between the N7 atoms of two adjacent guanines. Structure-function analysis has shown that translocation of a cisplatin lesion to register $+1 /+2$ is strongly disfavored [151]. When a cisplatin lesion reaches the $+2 /+3$ position, Pol II incorporates AMP at the +1 site in a non-templated manner, as for CPD transcription. In contrast to the CPD lesion, however, a cisplatin lesion cannot overcome the translocation barrier and enter the active site, likely due to its larger size. Pol II stalling at a cisplatin lesion is not due to misincorporation as in the case of a CPD lesion, but rather because the cisplatin lesion cannot be delivered to the active site. Taken together, polymerase stalling is triggered by misincorporation at a CPD lesion, whereas at a cisplatin lesion misincorporation is a result of stalling due to a translocation barrier.

In contrast to bulky lesions, Pol II can generally bypass small lesions, in particular lesions resulting from oxidative damage such as 8-oxoguanine (8-oxoG) [157-159]. Lesion bypass can result in transcriptional mutagenesis [160]. Structure-function analysis of Pol II ECs containing 8-oxoG in the template strand reveled the mechanism of mutagenic transcription at 8-oxoG lesions [161]. Pol II can incorporate a cytosine opposite an 8-oxoG forming a Watson-Crick base pair. However, adenine can also be incorporated, which forms a Hoogsteen base pair with the 8-oxoG lesion and escapes proofreading, resulting in transcriptional mutagenesis and a mutated RNA molecule. A model was proposed in which the incoming 8-oxoG adopts a standard anti-conformation within a Watson-Crick base pair. Subsequent rotation of the 8 -oxoG base by $180^{\circ}$ into the syn-conformation may occur in the pre-templating position, when the template base is unpaired [61], and can then lead to formation of a Hoogsteen base pair with adenine in the templating position +1 . In general, an encounter of Pol II with a lesion in the template strand can either lead to polymerase stalling and TCR, or to lesion bypass that may be accompanied by transcriptional mutagenesis. If TCR fails and Pol II remains stably stalled and inactive, its largest subunit Rpb1 can be ubiquitinated and degraded by the proteasome, leading to a loss of the EC from the transcribed gene [162]. Thus, in any case, cellular mechanisms exist that assure that gene transcription is not irreversibly blocked.

\section{Conclusions}

Here we summarize our current understanding of the molecular mechanisms underlying transcription elongation by cellular multisubunit RNA polymerases. Structure-function studies of ECs in many different states revealed a high conservation of elongation mechanisms across the three kingdoms of life. Many features of the EC were elucidated, including its structure, the nucleotide addition cycle including translocation, its inhibition, its pausing, backtracking, arrest and reactivation, its processivity, and its property to proofread the RNA after misincorporation and to recognize DNA lesions. In the future, mechanistic studies of transcription elongation should concentrate on the characterization of allosteric mechanisms and the conformational changes underlying these, and on a better understanding of how the many elongation factors control the EC. In the more distant future, structure-function studies may contribute to an investigation of context-dependent features of transcription elongation, including elongation through chromatin templates, cooperation of multiple ECs on the same template, and coordination of transcription elongation with DNA replication.

\section{Acknowledgements}

The authors would like to thank Dr. Carrie Bernecky, Dr. Alan Cheung, Dr. Sarah Sainsbury, and Kerstin Kinkelin for critical reading of the manuscript. FM was supported by the BGF. PC was supported by the DFG, SFB646, SFB960, GraKo1721, CIPSM, TR5, NIM, the BioImaging Network, an ERC Advanced Grant, the Jung-Stiftung, and the Vallee Foundation.

\section{References}

[1] P. Cramer, K.J. Armache, S. Baumli, S. Benkert, F. Brueckner, C. Buchen, G.E Damsma, S. Dengl, S.R. Geiger, A.J. Jasiak, A. Jawhari, S. Jennebach, T. Kamenski, H. Kettenberger, C.D. Kuhn, E. Lehmann, K. Leike, J.F. Sydow, A. Vannini, Structure of eukaryotic RNA polymerases, Annu. Rev. Biophys. 37 (2008) 337-352.

[2] P. Cramer, D.A. Bushnell, J. Fu, A.L. Gnatt, B. Maier-Davis, N.E. Thompson, R.R Burgess, A.M. Edwards, P.R. David, R.D. Kornberg, Architecture of RNA polymerase II and implications for the transcription mechanism, Science 288 (2000) 640-649.

[3] P. Cramer, D.A. Bushnell, R.D. Kornberg, Structural basis of transcription: RNA polymerase II at 2.8 angstrom resolution, Science 292 (2001) 1863-1876.

[4] D. Grohmann, F. Werner, Cycling through transcription with the RNA polymerase F/E (RPB4/7) complex: structure, function and evolution of archaeal RNA polymerase, Res. Microbiol. 162 (2011) 10-18.

[5] A. Hirata, B.J. Klein, K.S. Murakami, The X-ray crystal structure of RNA polymerase from Archaea, Nature 451 (2008) 851-854.

[6] Y. Korkhin, U.M. Unligil, O. Littlefield, P.J. Nelson, D.I. Stuart, P.B. Sigler, S.D. Bell, N.G. Abrescia, Evolution of complex RNA polymerases: the complete archaea RNA polymerase structure, PLoS Biol. 7 (2009) e102.

[7] D.G. Vassylyev, S. Sekine, O. Laptenko, J. Lee, M.N. Vassylyeva, S. Borukhov, S. Yokoyama, Crystal structure of a bacterial RNA polymerase holoenzyme at 2.6 Å resolution, Nature 417 (2002) 712-719.

[8] G. Zhang, E.A. Campbell, L. Minakhin, C. Richter, K. Severinov, S.A. Darst, Crystal structure of Thermus aquaticus core RNA polymerase at $3.3 \AA$ resolution, Cell 98 (1999) 811-824.

[9] J.R. Haag, C.S. Pikaard, Multisubunit RNA polymerases IV and V: purveyors of non-coding RNA for plant gene silencing, Nat. Rev. Mol. Cell Biol. 12 (2011) 483-492.

[10] R. Landick, Functional divergence in the growing family of RNA polymerases, Structure 17 (2009) 323-325.

[11] T.S. Ream, J.R. Haag, A.T. Wierzbicki, C.D. Nicora, A.D. Norbeck, J.K. Zhu, G. Hagen, T.J. Guilfoyle, L. Pasa-Tolic, C.S. Pikaard, Subunit compositions of the RNAsilencing enzymes Pol IV and Pol V reveal their origins as specialized forms of RNA polymerase II, Mol. Cell 33 (2009) 192-203.

[12] F. Werner, D. Grohmann, Evolution of multisubunit RNA polymerases in the three domains of life, Nat. Rev. Microbiol. 9 (2011) 85-98.

[13] G. Ruprich-Robert, P. Thuriaux, Non-canonical DNA transcription enzymes and the conservation of two-barrel RNA polymerases, Nucleic Acids Res. 38 (2010) 4559-4569.

[14] E. Lehmann, F. Brueckner, P. Cramer, Molecular basis of RNA-dependent RNA polymerase II activity, Nature 450 (2007) 445-449.

[15] P.S. Salgado, M.R. Koivunen, E.V. Makeyev, D.H. Bamford, D.I. Stuart, J.M. Grimes, The structure of an RNAi polymerase links RNA silencing and transcription, PLoS Biol. 4 (2006) e434. 
[16] A. Vannini, P. Cramer, Conservation between the RNA polymerase I, II, and III transcription initiation machineries, Mol. Cell 45 (2012) 439-446.

[17] D. Kostrewa, M.E. Zeller, K.J. Armache, M. Seizl, K. Leike, M. Thomm, P. Cramer, RNA polymerase II-TFIIB structure and mechanism of transcription initiation, Nature 462 (2009) 323-330.

[18] X. Liu, D.A. Bushnell, D. Wang, G. Calero, R.D. Kornberg, Structure of an RNA polymerase II-TFIB complex and the transcription initiation mechanism, Science 327 (2010) 206-209.

[19] A. Saunders, L.J. Core, J.T. Lis, Breaking barriers to transcription elongation, Nat. Rev. Mol. Cell Biol. 7 (2006) 557-567.

[20] L.A. Selth, S. Sigurdsson, J.Q. Svejstrup, Transcript elongation by RNA polymerase II, Annu. Rev. Biochem. 79 (2010) 271-293.

[21] A. Shilatifard, R.C. Conaway, J.W. Conaway, The RNA polymerase II elongation complex, Annu. Rev. Biochem. 72 (2003) 693-715.

[22] S.A. Darst, A.M. Edwards, E.W. Kubalek, R.D. Kornberg, Three-dimensional structure of yeast RNA polymerase II at 16 Å resolution, Cell 66 (1991) 121-128.

[23] F.J. Asturias, G.D. Meredith, C.L. Poglitsch, R.D. Kornberg, Two conformations of RNA polymerase II revealed by electron crystallography, J. Mol. Biol. 272 (1997) 536-540.

[24] G.J. Jensen, G. Meredith, D.A. Bushnell, R.D. Kornberg, Structure of wild-type yeast RNA polymerase II and location of Rpb4 and Rpb7, EMBO J. 17 (1998) 2353-2358.

[25] J.L. Craighead, W.H. Chang, F.J. Asturias, Structure of yeast RNA polymerase II in solution: implications for enzyme regulation and interaction with promoter DNA, Structure 10 (2002) 1117-1125.

[26] J. Fu, A.L. Gnatt, D.A. Bushnell, G.J. Jensen, N.E. Thompson, R.R. Burgess, P.R. David, R.D. Kornberg, Yeast RNA polymerase II at $5 \AA$ resolution, Cell 98 (1999) 799-810.

[27] A.L. Gnatt, P. Cramer, J. Fu, D.A. Bushnell, R.D. Kornberg, Structural basis of transcription: an RNA polymerase II elongation complex at 3.3 Å resolution, Science 292 (2001) 1876-1882.

[28] D.A. Bushnell, R.D. Kornberg, Complete, 12-subunit RNA polymerase II at 4.1-Å resolution: implications for the initiation of transcription, Proc. Natl. Acad. Sci. U. S. A. 100 (2003) 6969-6973.

[29] K.J. Armache, H. Kettenberger, P. Cramer, Architecture of initiation-competent 12-subunit RNA polymerase II, Proc. Natl. Acad. Sci. U. S. A. 100 (2003) 6964-6968.

[30] K.J. Armache, S. Mitterweger, A. Meinhart, P. Cramer, Structures of complete RNA polymerase II and its subcomplex, Rpb4/7, J. Biol. Chem. 280 (2005) 7131-7134.

[31] N. Korzheva, A. Mustaev, M. Kozlov, A. Malhotra, V. Nikiforov, A. Goldfarb, S.A. Darst, A structural model of transcription elongation, Science 289 (2000) 619-625.

[32] N. Naryshkin, A. Revyakin, Y. Kim, V. Mekler, R.H. Ebright, Structural organization of the RNA polymerase-promoter open complex, Cell 101 (2000) 601-611.

[33] N. Opalka, J. Brown, W.J. Lane, K.A. Twist, R. Landick, F.J. Asturias, S.A. Darst Complete structural model of Escherichia coli RNA polymerase from a hybrid approach, PLoS Biol. 8 (2010).

[34] D.G. Vassylyev, M.N. Vassylyeva, A. Perederina, T.H. Tahirov, I. Artsimovitch, Structural basis for transcription elongation by bacterial RNA polymerase, $\mathrm{Na}-$ ture 448 (2007) 157-162.

[35] D.G. Vassylyev, M.N. Vassylyeva, J. Zhang, M. Palangat, I. Artsimovitch, R. Landick, Structural basis for substrate loading in bacterial RNA polymerase, $\mathrm{Na}-$ ture 448 (2007) 163-168.

[36] T.H. Tahirov, D. Temiakov, M. Anikin, V. Patlan, W.T. McAllister, D.G. Vassylyev, S. Yokoyama, Structure of a T7 RNA polymerase elongation complex at 2.9 A resolution, Nature 420 (2002) 43-50.

[37] Y.W. Yin, T.A. Steitz, Structural basis for the transition from initiation to elongation transcription in T7 RNA polymerase, Science 298 (2002) 1387-1395.

[38] Y.W. Yin, T.A. Steitz, The structural mechanism of translocation and helicase activity in T7 RNA polymerase, Cell 116 (2004) 393-404.

[39] K.J. Durniak, S. Bailey, T.A. Steitz, The structure of a transcribing T7 RNA polymerase in transition from initiation to elongation, Science 322 (2008) 553-557.

[40] M.L. Gleghorn, E.K. Davydova, L.B. Rothman-Denes, K.S. Murakami, Structural basis for DNA-hairpin promoter recognition by the bacteriophage N4 virion RNA polymerase, Mol. Cell 32 (2008) 707-717.

[41] C.L. Poglitsch, G.D. Meredith, A.L. Gnatt, G.J. Jensen, W.H. Chang, J. Fu, R.D. Kornberg, Electron crystal structure of an RNA polymerase II transcription elongation complex, Cell 98 (1999) 791-798.

[42] W.A. Rees, R.W. Keller, J.P. Vesenka, G. Yang, C. Bustamante, Evidence of DNA bending in transcription complexes imaged by scanning force microscopy, Science 260 (1993) 1646-1649.

[43] E. Nudler, Transcription elongation: structural basis and mechanisms, J. Mol. Biol. 288 (1999) 1-12.

[44] E. Nudler, E. Avetissova, V. Markovtsov, A. Goldfarb, Transcription processivity: protein-DNA interactions holding together the elongation complex, Science 273 (1996) 211-217.

[45] E. Nudler, I. Gusarov, E. Avetissova, M. Kozlov, A. Goldfarb, Spatial organization of transcription elongation complex in Escherichia coli, Science 281 (1998) 424-428.

[46] M.S. Bartlett, M. Thomm, E.P. Geiduschek, The orientation of DNA in an archaeal transcription initiation complex, Nat. Struct. Biol. 7 (2000) 782-785.

[47] K.D. Westover, D.A. Bushnell, R.D. Kornberg, Structural basis of transcription nucleotide selection by rotation in the RNA polymerase II active center, Cell 119 (2004) 481-489.

[48] K.D. Westover, D.A. Bushnell, R.D. Kornberg, Structural basis of transcription: separation of RNA from DNA by RNA polymerase II, Science 303 (2004) 1014-1016.
[49] H. Kettenberger, K.J. Armache, P. Cramer, Complete RNA polymerase II elongation complex structure and its interactions with NTP and TFIS, Mol. Cell 16 (2004) 955-965.

[50] M. Pal, A.S. Ponticelli, D.S. Luse, The role of the transcription bubble and TFIIB in promoter clearance by RNA polymerase II, Mol. Cell 19 (2005) 101-110.

[51] J. Andrecka, R. Lewis, F. Bruckner, E. Lehmann, P. Cramer, J. Michaelis, Single-molecule tracking of mRNA exiting from RNA polymerase II, Proc. Natl. Acad. Sci. U. S. A. 105 (2008) 135-140.

[52] J. Andrecka, B. Treutlein, M.A. Arcusa, A. Muschielok, R. Lewis, A.C. Cheung, P. Cramer, J. Michaelis, Nano positioning system reveals the course of upstream and nontemplate DNA within the RNA polymerase II elongation complex, Nucleic Acids Res. 37 (2009) 5803-5809.

[53] V. Trinh, M.F. Langelier, J. Archambault, B. Coulombe, Structural perspective on mutations affecting the function of multisubunit RNA polymerases, Microbiol. Mol. Biol. Rev. 70 (2006) 12-36.

[54] S. Naji, M.G. Bertero, P. Spitalny, P. Cramer, M. Thomm, Structure-function analysis of the RNA polymerase cleft loops elucidates initial transcription, DNA unwinding and RNA displacement, Nucleic Acids Res. 36 (2008) 676-687.

[55] M.L. Kireeva, C. Domecq, B. Coulombe, Z.F. Burton, M. Kashlev, Interaction of RNA polymerase II fork loop 2 with downstream non-template DNA regulates transcription elongation, J. Biol. Chem. 286 (2011) 30898-30910.

[56] T. Naryshkina, K. Kuznedelov, K. Severinov, The role of the largest RNA polymerase subunit lid element in preventing the formation of extended RNA-DNA hybrid, J. Mol. Biol. 361 (2006) 634-643.

[57] I. Toulokhonov, R. Landick, The role of the lid element in transcription by E. coli RNA polymerase, J. Mol. Biol. 361 (2006) 644-658.

[58] K. Kuznedelov, N. Korzheva, A. Mustaev, K. Severinov, Structure-based analysis of RNA polymerase function: the largest subunit's rudder contributes critically to elongation complex stability and is not involved in the maintenance of RNA-DNA hybrid length, EMBO J. 21 (2002) 1369-1378.

[59] D. Wang, D.A. Bushnell, K.D. Westover, C.D. Kaplan, R.D. Kornberg, Structural basis of transcription: role of the trigger loop in substrate specificity and catalysis, Cell 127 (2006) 941-954.

[60] A.C. Cheung, S. Sainsbury, P. Cramer, Structural basis of initial RNA polymerase II transcription, EMBO J. 30 (2011) 4755-4763.

[61] F. Brueckner, P. Cramer Structural basis of transcription inhibition by alpha-amanitin and implications for RNA polymerase II translocation, Nat. Struct. Mol. Biol. 15 (2008) 811-818.

[62] J. Zhang, M. Palangat, R. Landick, Role of the RNA polymerase trigger loop in catalysis and pausing, Nat. Struct. Mol. Biol. 17 (2010) 99-104.

[63] F. Brueckner, J. Ortiz, P. Cramer, A movie of the RNA polymerase nucleotide addition cycle, Curr. Opin. Struct. Biol. 19 (2009) 294-299.

[64] P. Cramer, Gene transcription: extending the message, Nature 448 (2007) $142-143$.

[65] S.R. Kennedy, D.A. Erie, Templated nucleoside triphosphate binding to a noncatalytic site on RNA polymerase regulates transcription, Proc. Natl. Acad. Sci. U. S. A. 108 (2011) 6079-6084.

[66] Y.A. Nedialkov, X.Q. Gong, S.L. Hovde, Y. Yamaguchi, H. Handa, J.H. Geiger, H. Yan, Z.F. Burton, NTP-driven translocation by human RNA polymerase II, J. Biol. Chem. 278 (2003) 18303-18312.

[67] M.L. Kireeva, Y.A. Nedialkov, G.H. Cremona, Y.A. Purtov, L. Lubkowska, F. Malagon, Z.F. Burton, J.N. Strathern, M. Kashlev, Transient reversal of RNA polymerase II active site closing controls fidelity of transcription elongation, Mol. Cell 30 (2008) 557-566.

[68] D. Temiakov, V. Patlan, M. Anikin, W.T. McAllister, S. Yokoyama, D.G. Vassylyev, Structural basis for substrate selection by t7 RNA polymerase, Cell 116 (2004) 381-391.

[69] V. Sosunov, E. Sosunova, A. Mustaev, I. Bass, V. Nikiforov, A. Goldfarb, Unified two-metal mechanism of RNA synthesis and degradation by RNA polymerase, EMBO J. 22 (2003) 2234-2244.

[70] T.A. Steitz, S.J. Smerdon, J. Jager, C.M. Joyce, A unified polymerase mechanism for nonhomologous DNA and RNA polymerases, Science 266 (1994) 2022-2025.

[71] T.A. Steitz, A mechanism for all polymerases, Nature 391 (1998) 231-232.

[72] E.A. Abbondanzieri, W.J. Greenleaf, J.W. Shaevitz, R. Landick, S.M. Block, Direct observation of base-pair stepping by RNA polymerase, Nature 438 (2005) $460-465$.

[73] M. Feig, Z.F. Burton, RNA polymerase II with open and closed trigger loops: active site dynamics and nucleic acid translocation, Biophys. J. 99 (2010) $2577-2586$.

[74] V. Svetlov, D.G. Vassylyev, I. Artsimovitch, Discrimination against deoxyribonucleotide substrates by bacterial RNA polymerase, J. Biol. Chem. 279 (2004) $38087-38090$.

[75] C.D. Kaplan, K.M. Larsson, R.D. Kornberg, The RNA polymerase II trigger loop functions in substrate selection and is directly targeted by alpha-amanitin, Mol. Cell 30 (2008) 547-556.

[76] H. Kettenberger, K.J. Armache, P. Cramer, Architecture of the RNA polymerase IITFIIS complex and implications for mRNA cleavage, Cell 114 (2003) 347-357.

[77] F. Brueckner, K.J. Armache, A. Cheung, G.E. Damsma, H. Kettenberger, E. Lehmann, J. Sydow, P. Cramer, Structure-function studies of the RNA polymerase II elongation complex, Acta Crystallogr. D Biol. Crystallogr. 65 (2009) $112-120$.

[78] I. Artsimovitch, M.N. Vassylyeva, D. Svetlov, V. Svetlov, A. Perederina, N. Igarashi, N. Matsugaki, S. Wakatsuki, T.H. Tahirov, D.G. Vassylyev, Allosteric modulation of the RNA polymerase catalytic reaction is an essential component of transcription control by rifamycins, Cell 122 (2005) 351-363.

[79] S. Tuske, S.G. Sarafianos, X. Wang, B. Hudson, E. Sineva, J. Mukhopadhyay, J. Birktoft, O. Leroy, S. Ismail, A.D. Clark Jr., C. Dharia, A. Napoli, O. Laptenko, J. Lee, S. 
Borukhov, R.H. Ebright, E. Arnold, Inhibition of bacterial RNA polymerase by streptolydigin: stabilization of a straight-bridge-helix active-center conformation, Cell 122 (2005) 541-552.

[80] G. Bar-Nahum, V. Epshtein, A.E. Ruckenstein, R. Rafikov, A. Mustaev, E. Nudler, A ratchet mechanism of transcription elongation and its control, Cell 120 (2005) 183-193.

[81] V. Epshtein, A. Mustaev, V. Markovtsov, O. Bereshchenko, V. Nikiforov, A. Goldfarb, Swing-gate model of nucleotide entry into the RNA polymerase active center, Mol. Cell 10 (2002) 623-634.

[82] R.O. Weinzierl, The bridge helix of RNA polymerase acts as a central nanomechanical switchboard for coordinating catalysis and substrate movement, Archaea 2011 (2011) 608385.

[83] F. Malagon, M.L. Kireeva, B.K. Shafer, L. Lubkowska, M. Kashlev, J.N. Strathern, Mutations in the Saccharomyces cerevisiae RPB1 gene conferring hypersensitivity to 6-azauracil, Genetics 172 (2006) 2201-2209.

[84] M. Kireeva, M. Kashlev, Z.F. Burton, Translocation by multi-subunit RNA polymerases, Biochim. Biophys. Acta 1799 (2010) 389-401.

[85] P.P. Hein, M. Palangat, R. Landick, RNA transcript 3'-proximal sequence affects translocation bias of RNA polymerase, Biochemistry 50 (2011) 7002-7014

[86] A.C. Cheung, P. Cramer, A movie of RNA polymerase II transcription, Cell 149 (2012) 1431-1437.

[87] D.A. Bushnell, P. Cramer, R.D. Kornberg, Structural basis of transcription: alpha-amanitin-RNA polymerase II cocrystal at $2.8 \AA$ resolution, Proc. Natl. Acad. Sci. U. S. A. 99 (2002) 1218-1222.

[88] X.Q. Gong, Y.A. Nedialkov, Z.F. Burton, Alpha-amanitin blocks translocation by human RNA polymerase II, J. Biol. Chem. 279 (2004) 27422-27427.

[89] F. Brueckner, P. Cramer, Structural basis of transcription inhibition by alpha-amanitin and implications for RNA polymerase II translocation, Nat. Struct. Mol. Biol. 15 (2008) 811-818.

[90] L.T. Da, D. Wang, X. Huang, Dynamics of pyrophosphate ion release and its coupled trigger loop motion from closed to open state in RNA polymerase II, J. Am. Chem. Soc. 134 (2012) 2399-2406.

[91] D.G. Vassylyev, Elongation by RNA polymerase: a race through roadblocks, Curr. Opin. Struct. Biol. 19 (2009) 691-700.

[92] D. Temiakov, N. Zenkin, M.N. Vassylyeva, A. Perederina, T.H. Tahirov, E. Kashkina, M. Savkina, S. Zorov, V. Nikiforov, N. Igarashi, N. Matsugaki, S. Wakatsuki, K. Severinov, D.G. Vassylyev, Structural basis of transcription inhibition by antibiotic streptolydigin, Mol. Cell 19 (2005) 655-666.

[93] D.G. Vassylyev, V. Svetlov, M.N. Vassylyeva, A. Perederina, N. Igarashi, N. Matsugaki, S. Wakatsuki, I. Artsimovitch, Structural basis for transcription inhibition by tagetitoxin, Nat. Struct. Mol. Biol. 12 (2005) 1086-1093.

[94] I. Artsimovitch, V. Svetlov, S.M. Nemetski, V. Epshtein, T. Cardozo, E. Nudler, Tagetitoxin inhibits RNA polymerase through trapping of the trigger loop, J. Biol. Chem. 286 (2011) 40395-40400.

[95] S. Klyuyev, D.G. Vassylyev, The binding site and mechanism of the RNA polymerase inhibitor tagetitoxin: an issue open to debate, Transcription 3 (2012) 46-50.

[96] V. Svetlov, I. Artsimovitch, E. Nudler, Response to Klyuyev and Vassylyev: on the mechanism of tagetitoxin inhibition of transcription, Transcription 3 (2012) 51-55.

[97] S. Tagami, S. Sekine, T. Kumarevel, N. Hino, Y. Murayama, S. Kamegamori, M. Yamamoto, K. Sakamoto, S. Yokoyama, Crystal structure of bacterial RNA polymerase bound with a transcription inhibitor protein, Nature 468 (2010) 978-982.

[98] E.A. Campbell, N. Korzheva, A. Mustaev, K. Murakami, S. Nair, A. Goldfarb, S.A Darst, Structural mechanism for rifampicin inhibition of bacterial RNA polymerase, Cell 104 (2001) 901-912.

[99] J.L. Knight, V. Mekler, J. Mukhopadhyay, R.H. Ebright, R.M. Levy, Distance-restrained docking of rifampicin and rifamycin SV to RNA polymerase using systematic FRET measurements: developing benchmarks of model quality and reliability, Biophys. J. 88 (2005) 925-938.

[100] E.A. Campbell, O. Pavlova, N. Zenkin, F. Leon, H. Irschik, R. Jansen, K. Severinov, S.A. Darst, Structural, functional, and genetic analysis of sorangicin inhibition of bacterial RNA polymerase, EMBO J. 24 (2005) 674-682.

[101] G.A. Belogurov, M.N. Vassylyeva, A. Sevostyanova, J.R. Appleman, A.X. Xiang, R. Lira, S.E. Webber, S. Klyuyev, E. Nudler, I. Artsimovitch, D.G. Vassylyev, Transcription inactivation through local refolding of the RNA polymerase structure, Nature 457 (2009) 332-335.

[102] R. Landick, The regulatory roles and mechanism of transcriptional pausing, Biochem. Soc. Trans. 34 (2006) 1062-1066.

[103] I. Toulokhonov, J. Zhang, M. Palangat, R. Landick, A central role of the RNA polymerase trigger loop in active-site rearrangement during transcriptional pausing, Mol. Cell 27 (2007) 406-419.

[104] J.F. Sydow, F. Brueckner, A.C. Cheung, G.E. Damsma, S. Dengl, E. Lehmann, D. Vassylyev, P. Cramer, Structural basis of transcription: mismatch-specific fidelity mechanisms and paused RNA polymerase II with frayed RNA, Mol. Cell 34 (2009) 710-721.

[105] J.F. Sydow, P. Cramer, RNA polymerase fidelity and transcriptional proofreading, Curr. Opin. Struct. Biol. 19 (2009) 732-739.

[106] N. Alic, N. Ayoub, E. Landrieux, E. Favry, P. Baudouin-Cornu, M. Riva, C. Carles, Selectivity and proofreading both contribute significantly to the fidelity of RNA polymerase III transcription, Proc. Natl. Acad. Sci. U. S. A. 104 (2007) 10400-10405.

[107] A.C. Cheung, P. Cramer, Structural basis of RNA polymerase II backtracking, arrest and reactivation, Nature 471 (2011) 249-253.

[108] M.J. Thomas, A.A. Platas, D.K. Hawley, Transcriptional fidelity and proofreading by RNA polymerase II, Cell 93 (1998) 627-637.

[109] D. Wang, D.A. Bushnell, X. Huang, K.D. Westover, M. Levitt, R.D. Kornberg, Structural basis of transcription: backtracked RNA polymerase II at 3.4 angstrom resolution, Science 324 (2009) 1203-1206.
[110] N. Zenkin, Y. Yuzenkova, K. Severinov, Transcript-assisted transcriptional proofreading, Science 313 (2006) 518-520.

[111] M.L. Kireeva, B. Hancock, G.H. Cremona, W. Walter, V.M. Studitsky, M. Kashlev Nature of the nucleosomal barrier to RNA polymerase II, Mol. Cell 18 (2005) 97-108.

[112] E. Nudler, A. Mustaev, E. Lukhtanov, A. Goldfarb, The RNA-DNA hybrid maintains the register of transcription by preventing backtracking of RNA polymerase, Cell 89 (1997) 33-41.

[113] N. Komissarova, M. Kashlev, Transcriptional arrest: Escherichia coli RNA polymerase translocates backward, leaving the $3^{\prime}$ end of the RNA intact and extruded, Proc. Natl. Acad. Sci. U. S. A. 94 (1997) 1755-1760.

[114] R.N. Fish, C.M. Kane, Promoting elongation with transcript cleavage stimulatory factors, Biochim. Biophys. Acta 1577 (2002) 287-307.

[115] M.N. Vassylyeva, V. Svetlov, A.D. Dearborn, S. Klyuyev, I. Artsimovitch, D.G. Vassylyev, The carboxy-terminal coiled-coil of the RNA polymerase beta' subunit is the main binding site for Gre factors, EMBO Rep. 8 (2007) 1038-1043.

[116] N. Opalka, M. Chlenov, P. Chacon, W.J. Rice, W. Wriggers, S.A. Darst, Structure and function of the transcription elongation factor GreB bound to bacterial RNA polymerase, Cell 114 (2003) 335-345.

[117] M. Roghanian, Y. Yuzenkova, N. Zenkin, Controlled interplay between trigger loop and Gre factor in the RNA polymerase active centre, Nucleic Acids Res. 39 (2011) 4352-4359.

[118] C.E. Stebbins, S. Borukhov, M. Orlova, A. Polyakov, A. Goldfarb, S.A. Darst, Crystal structure of the GreA transcript cleavage factor from Escherichia coli, Nature 373 (1995) 636-640.

[119] M.G. Izban, D.S. Luse, The RNA polymerase II ternary complex cleaves the nascent transcript in a $3^{\prime}-5^{\prime}$ direction in the presence of elongation factor SII Genes Dev. 6 (1992) 1342-1356.

[120] V.K. Olmsted, D.E. Awrey, C. Koth, X. Shan, P.E. Morin, S. Kazanis, A.M. Edwards, C.H. Arrowsmith, Yeast transcript elongation factor (TFIS), structure and function. I: NMR structural analysis of the minimal transcriptionally active region, J. Biol. Chem. 273 (1998) 22589-22594.

[121] V. Booth, C.M. Koth, A.M. Edwards, C.H. Arrowsmith, Structure of a conserved domain common to the transcription factors TFIIS, elongin A, and CRSP70, J. Biol Chem. 275 (2000) 31266-31268.

[122] W. Powell, B. Bartholomew, D. Reines, Elongation factor SII contacts the 3'-end of RNA in the RNA polymerase II elongation complex, J. Biol. Chem. 271 (1996) 22301-22304.

[123] M.D. Rudd, M.G. Izban, D.S. Luse, The active site of RNA polymerase II participates in transcript cleavage within arrested ternary complexes, Proc. Natl. Acad. Sci. U. S. A. 91 (1994) 8057-8061.

[124] Z.Y. Wang, X.H. Lin, M. Nobuyoshi, T.F. Deuel, Identification of a single-stranded DNA-binding protein that interacts with an S1 nuclease-sensitive region in the platelet-derived growth factor A-chain gene promoter, J. Biol. Chem. 268 (1993) 10681-10685.

[125] M.L. Kireeva, N. Komissarova, D.S. Waugh, M. Kashlev, The 8-nucleotide-long RNA:DNA hybrid is a primary stability determinant of the RNA polymerase II elongation complex, J. Biol. Chem. 275 (2000) 6530-6536.

[126] K.M. Herbert, A. La Porta, B.J. Wong, R.A. Mooney, K.C. Neuman, R. Landick, S.M Block, Sequence-resolved detection of pausing by single RNA polymerase molecules, Cell 125 (2006) 1083-1094.

[127] A. Hirtreiter, D. Grohmann, F. Werner, Molecular mechanisms of RNA polymerase-the $\mathrm{F} / \mathrm{E}(\mathrm{RPB} 4 / 7)$ complex is required for high processivity in vitro, Nucleic Acids Res. 38 (2010) 585-596.

[128] K.M. Herbert, J. Zhou, R.A. Mooney, A.L. Porta, R. Landick, S.M. Block, E. coli NusC inhibits backtracking and accelerates pause-free transcription by promoting forward translocation of RNA polymerase, J. Mol. Biol. 399 (2010) 17-30.

[129] A. Hirtreiter, G.E. Damsma, A.C. Cheung, D. Klose, D. Grohmann, E. Vojnic, A.C. Martin, P. Cramer, F. Werner, Spt4/5 stimulates transcription elongation through the RNA polymerase clamp coiled-coil motif, Nucleic Acids Res. 38 (2010) 4040-4051.

[130] F. Werner, A nexus for gene expression-molecular mechanisms of Spt5 and NusG in the three domains of life, J. Mol. Biol. 417 (2012) 13-27.

[131] S. Borukhov, E. Nudler, RNA polymerase: the vehicle of transcription, Trends Microbiol. 16 (2008) 126-134.

[132] G.A. Belogurov, R.A. Mooney, V. Svetlov, R. Landick, I. Artsimovitch, Functional specialization of transcription elongation factors, EMBO J. 28 (2009) 112-122.

[133] R.A. Mooney, K. Schweimer, P. Rosch, M. Gottesman, R. Landick, Two structurally independent domains of $E$. coli NusG create regulatory plasticity via distinct interactions with RNA polymerase and regulators, J. Mol. Biol. 391 (2009) 341-358.

[134] I. Artsimovitch, R. Landick, The transcriptional regulator RfaH stimulates RNA chain synthesis after recruitment to elongation complexes by the exposed nontemplate DNA strand, Cell 109 (2002) 193-203.

[135] B.J. Klein, D. Bose, K.J. Baker, Z.M. Yusoff, X. Zhang, K.S. Murakami, RNA polymerase and transcription elongation factor Spt4/5 complex structure, Proc. Natl Acad. Sci. U. S. A. 108 (2011) 546-550.

[136] A. Sevostyanova, G.A. Belogurov, R.A. Mooney, R. Landick, I. Artsimovitch, The beta subunit gate loop is required for RNA polymerase modification by RfaH and NusG, Mol. Cell 43 (2011) 253-262.

[137] F.W. Martinez-Rucobo, S. Sainsbury, A.C. Cheung, P. Cramer, Architecture of the RNA polymerase-Spt4/5 complex and basis of universal transcription processivity, EMBO J. 30 (2011) 1302-1310.

[138] A. Sevostyanova, I. Artsimovitch, Functional analysis of Thermus thermophilus transcription factor NusG, Nucleic Acids Res. 38 (2010) 7432-7445. 
[139] A. Mayer, A. Schreieck, M. Lidschreiber, K. Leike, D.E. Martin, P. Cramer, The spt5 C-terminal region recruits yeast 3' RNA cleavage factor I, Mol. Cell. Biol. 32 (2012) 1321-1331.

[140] Y. Liu, L. Warfield, C. Zhang, J. Luo, J. Allen, W.H. Lang, J. Ranish, K.M. Shokat, S. Hahn, Phosphorylation of the transcription elongation factor Spt5 by yeast Bur1 kinase stimulates recruitment of the PAF complex, Mol. Cell. Biol. 29 (2009) 4852-4863.

[141] K. Zhou, W.H. Kuo, J. Fillingham, J.F. Greenblatt, Control of transcriptional elongation and cotranscriptional histone modification by the yeast BUR kinase substrate Spt5, Proc. Natl. Acad. Sci. U. S. A. 106 (2009) 6956-6961.

[142] S.L. Squazzo, P.J. Costa, D.L. Lindstrom, K.E. Kumer, R. Simic, J.L. Jennings, A.J. Link, K.M. Arndt, G.A. Hartzog, The Paf1 complex physically and functionally associates with transcription elongation factors in vivo, EMBO J. 21 (2002) 1764-1774.

[143] S.E. Polo, S.P. Jackson, Dynamics of DNA damage response proteins at DNA breaks: a focus on protein modifications, Genes Dev. 25 (2011) 409-433.

[144] F. Brueckner, P. Cramer, DNA photodamage recognition by RNA polymerase II, FEBS Lett. 581 (2007) 2757-2760.

[145] A. Sarasin, A. Stary, New insights for understanding the transcription-coupled repair pathway, DNA Repair (Amst) 6 (2007) 265-269.

[146] T.T. Saxowsky, P.W. Doetsch, RNA polymerase encounters with DNA damage: transcription-coupled repair or transcriptional mutagenesis? Chem. Rev. 106 (2006) 474-488.

[147] A.M. Deaconescu, A.L. Chambers, A.J. Smith, B.E. Nickels, A. Hochschild, N. Savery, S.A. Darst, Structural basis for bacterial transcription-coupled DNA repair, Cell 124 (2006) 507-520.

[148] L.F. Westblade, E.A. Campbell, C. Pukhrambam, J.C. Padovan, B.E. Nickels, V. Lamour, S.A. Darst, Structural basis for the bacterial transcription-repair coupling factor/RNA polymerase interaction, Nucleic Acids Res. 38 (2010) 8357-8369.

[149] P.C. Hanawalt, G. Spivak, Transcription-coupled DNA repair: two decades of progress and surprises, Nat. Rev. Mol. Cell Biol. 9 (2008) 958-970.

[150] F. Brueckner, U. Hennecke, T. Carell, P. Cramer, CPD damage recognition by transcribing RNA polymerase II, Science 315 (2007) 859-862.
[151] G.E. Damsma, A. Alt, F. Brueckner, T. Carell, P. Cramer, Mechanism of transcriptional stalling at cisplatin-damaged DNA, Nat. Struct. Mol. Biol. 14 (2007) 1127-1133.

[152] J.S. Taylor, New structural and mechanistic insight into the A-rule and the instructional and non-instructional behavior of DNA photoproducts and other lesions, Mutat. Res. 510 (2002) 55-70.

[153] J.S. Mei Kwei, I. Kuraoka, K. Horibata, M. Ubukata, E. Kobatake, S. Iwai, H. Handa, K. Tanaka, Blockage of RNA polymerase II at a cyclobutane pyrimidine dimer and 6-4 photoproduct, Biochem. Biophys. Res. Commun. 320 (2004) 1133-1138.

[154] C. Walmacq, A.C. Cheung, M.L. Kireeva, L. Lubkowska, C. Ye, D. Gotte, J.N. Strathern, T. Carell, P. Cramer, M. Kashlev, Mechanism of translesion transcription by RNA polymerase II and its role in cellular resistance to DNA damage, Mol. Cell 46 (2012) 18-29.

[155] S. Tornaletti, S.M. Patrick, J.J. Turchi, P.C. Hanawalt, Behavior of T7 RNA polymerase and mammalian RNA polymerase II at site-specific cisplatin adducts in the template DNA, J. Biol. Chem. 278 (2003) 35791-35797.

[156] D. Wang, S.J. Lippard, Cellular processing of platinum anticancer drugs, Nat. Rev. Drug Discov. 4 (2005) 307-320.

[157] T. Lindahl, Instability and decay of the primary structure of DNA, Nature 362 (1993) 709-715

[158] M. Dizdaroglu, P. Jaruga, M. Birincioglu, H. Rodriguez, Free radical-induced damage to DNA: mechanisms and measurement, Free Radic. Biol. Med. 32 (2002) $1102-1115$.

[159] N. Charlet-Berguerand, S. Feuerhahn, S.E. Kong, H. Ziserman, J.W. Conaway, R. Conaway, J.M. Egly, RNA polymerase II bypass of oxidative DNA damage is regulated by transcription elongation factors, EMBO J. 25 (2006) 5481-5491.

[160] D. Bregeon, P.W. Doetsch, Transcriptional mutagenesis: causes and involvement in tumour development, Nat. Rev. Cancer 11 (2011) 218-227.

[161] G.E. Damsma, P. Cramer, Molecular basis of transcriptional mutagenesis at 8-oxoguanine, J. Biol. Chem. 284 (2009) 31658-31663.

[162] J.Q. Svejstrup, Contending with transcriptional arrest during RNAPII transcript elongation, Trends Biochem. Sci. 32 (2007) 165-171. 